\title{
Theoretical Study for Electronic and Vibrational properties of nano cylinder $\left(\mathrm{C}_{140} \mathrm{H}_{28}\right)$.
}

\author{
Huda N. AL-Ani ${ }^{1}$ \\ ${ }^{I}$ Department of Chemistry, College of Science, University of Baghdad Jadiriya, Baghdad, Iraq
}

\begin{abstract}
Semi-empirical methods were applied for calculating the vibration frequencies and IR absorption intensities for normal coordinates of the (armchair nano cylinder) $\left(C_{140} H_{28}\right)$ single wall carbon nanotube(SWCNT) at equilibrium geometry which was found to has $D_{7} d$ symmetry point group. Assignment of the modes of vibration ( $3 N-6)$ was done depending on the pictures of their modes by applying (Gaussian 03) program. Comparison of the vibration frequencies of the nanotube which are active in $I R$, and inactive in Ramman spectra. For $C-H$ stretching vibrations. The results show the relation for axial bonds, which are the vertical C-C bonds (annular bonds) in the rings and for circumferential bonds which are the outer ring bonds. Also include the assignment of puckering, breathing and clock-anticlockwise bending vibrations. They allow a comparative view of the charge density at the carbon atom too.
\end{abstract}

Keywords: SWCNT single wall carbon nano tube; G03 aprogram for calculation. ; $\gamma$ : Out of plane modes of the molecule; $\delta$ : In-plane modes of the molecule.

\section{Introduction}

Carbon nanotubes were discovered in 1991 by Iijima [1]. Since then, efforts in synthesis, characterization and theoretical investigation on nanotubes have grown exponentially. This is mostly due to their perceived novel mechanical and electronic properties and their tremendous potential for future technological applications. In 1993, the simplest kind of carbon nanotubes, single-walled carbon nanotubes (SWNTs), were discovered independently by the Iijima group [2] and an IBM team headed by Bethune [3]. These SWNTs can be regarded as a rolled-up graphite sheet in cylindrical form. Some specific defect-free forms of these SWNTs show remarkable mechanical properties and metallic behavior [4]. These materials present tremendous potential as components for use in nano-electronic and nano-mechanical device applications or as structural elements in various devices. New and exciting phenomena have been observed[5], including field emission [6],quantum conductance [7], superconductivity[8], and higher thermal conductivity than diamond[9]. Depending upon structure, the nanotubes are either metallic or insulating, which is a feature that has been intensively investigated and exploited in prototype devices [5]. CNTs are extraordinarily flexible and do not break upon mechanical deformation. For example, they can be bent mechanically by mechanical milling, or by embedding the tubes in a polymeric resin[10], [11-13].

The vibrational modes of nanoscale spheres and tubes have been of great interest recently with advances in techniques for fabricating or synthesizing these structures [14]. Even for such small systems, continuum models are known to yield useful approximate description and provide valuable insight. Continuum models have been successfully used to study embedded nanoscale structures in two and one dimension such as heterostructures[15] They have also been applied to nonembedded nanoscale structures. For example, the continuum model has been used in the study of the radial breathing mode frequencies of nanospheres, including the effects of damping due to environmental interactions[16-18]. Also, the model has been applied to the study of both the normal modes and the energetics of fullerenes. [19,20] In such continuum models, the nanoscale properties of a material are frequently described with adequate accuracy by its bulk elastic properties[21]. As discussed in the previous work, nanotube deformation has been examined experimentally. Recent investigations have shown that carbon nanotubes possess remarkable mechanical properties, such as exceptionally high elastic modulus [22,23], large elastic strain and fracture strain sustaining capability[24,25]. Similar conclusions have also been reached through some theoretical studies[26-29] although very few correlations between theoretical predictions and experimental studies have been made. 


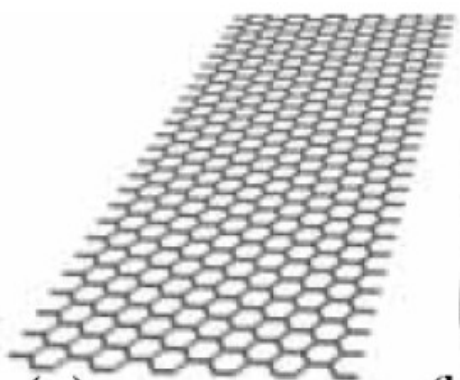

(a)

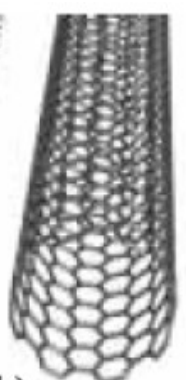

(b)

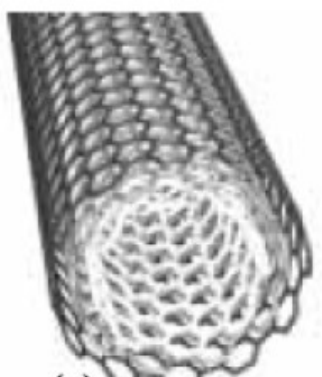

(c)

"Fig. 1": Carbon Nanotubes are made of single graphene sheets. (a) Shows cut-out part of a graphite lattice, (b) Shows a SWCNT, (c) Shows MWCNT where several CNTs are nested concentrically

\section{Methods of calculation}

Both G03 program by PM3 method [30], and Mopac 2000 program by PM3 method, Computational Packages have been employed throughout this study to compute the geometrical Parameters (bond lengths and bond angles) and the energetic properties [31] were applied throughout the present work.

\section{Results and Discussion.}

To study the vibration motions of such molecules, one has to define its geometric parameters, and has to distinguish between the axial CC (C-Caxial) bonds and circumferential CC (C-Cc) bonds, (figure.2) shows the two types of bonds in an armchair CNT [32].

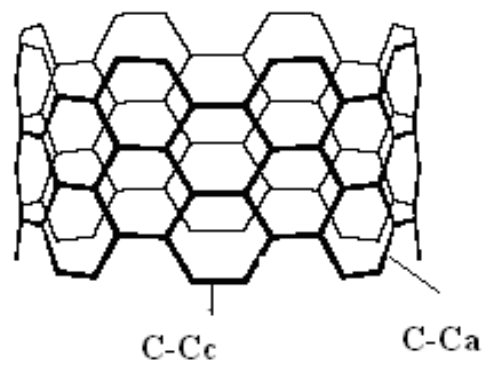

"Fig.2": Structure of armchair CNT, indicating the two types of C-C bonds; C-Caxial (C-Ca) and CCcircumferential (C-Cc).

Various quantum mechanical studies were done for the physical properties of the nanotubes [33-36]. Structure deformation is expected to change their thermal and electronic properties too. Basic vibrations of SWCNTs were measured and assigned as breathing, puckering and clock-anti-clockwise deformation modes [37]. They are considered as finger print vibrations for the carbon nanotubes (CNTs) [38]. The active vibrations causes a change in its geometry structure "Fig. 3", The calculation gives different geometry were done to study the impact of the puckering distortion on the electronic properties of CNTs [39-41]. For a normal mode of vibration to be infrared active, there must be a change in the dipole moment of the molecule during the course of vibration. During the vibration motion of a molecule, a regular fluctuation in the dipole moment occurs, and a field is established which can interact with the electrical field associated with radiation. For the absorption of infrared radiation, a molecule must undergo a net change in its dipole moment as a result of its vibrational or rotational motions [42]. 


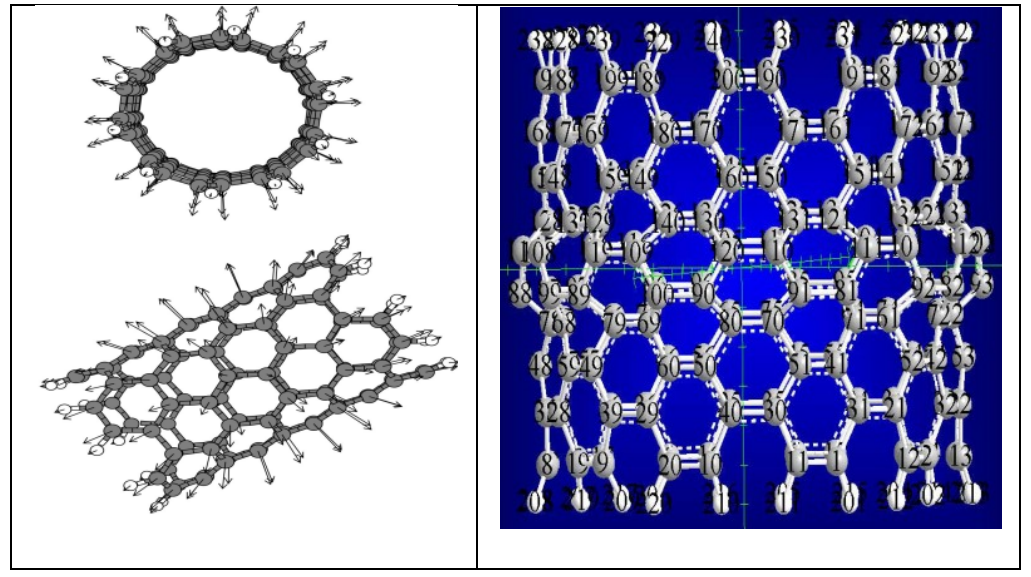

"Fig. 3": Structure deformation of a SWCNT as caused by its vibration motion

The classifications of carbon nanotube (armchair nano cylinder), determined by the typ (armchair) of the tube, can also be described as single-walled nanotube (SWNT), resembling by rolling a graphene sheet into a cylinder mathematically structures are uniquely defined by specifying the coordinates of the smallest folding vector $(n, n)$, (armchair) molecule. The (PM3) calculated equilibrium geometry shows $D_{7} d$ symmetry [43-44], "Fig. 4".
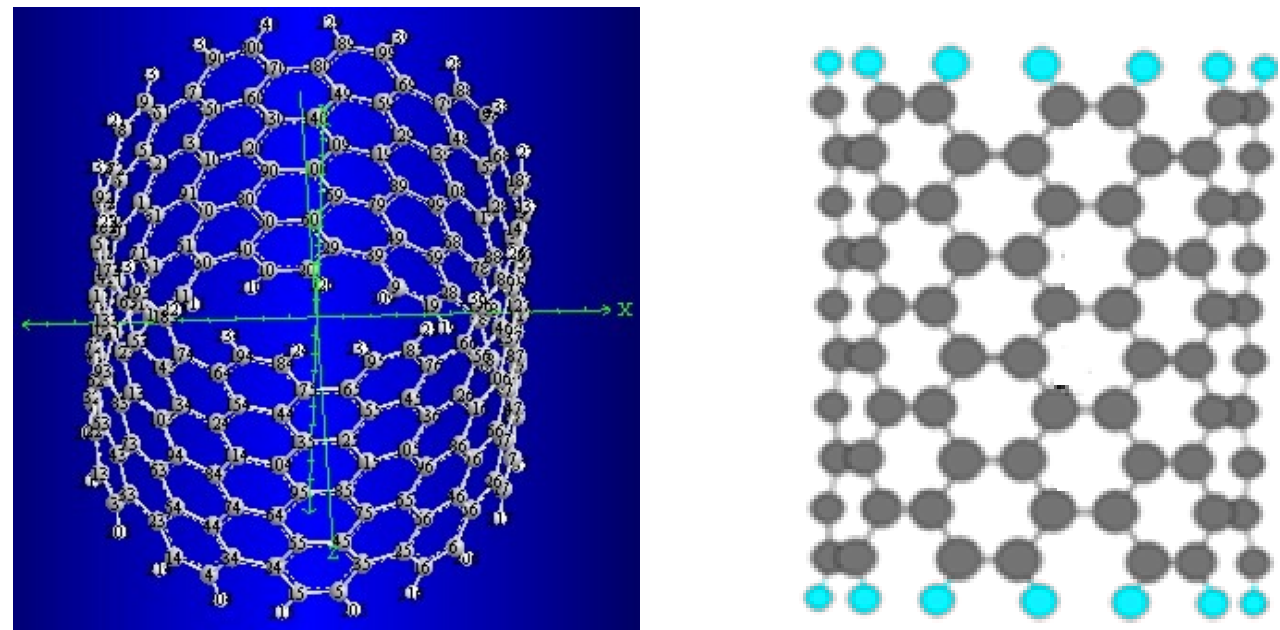

"Fig. 4".: Equilibrium geometry of carbon nanotube

((armchair nano cylinder))single wall carbon nanotube (SWCNT) by using Mopac 2000 program. $\mathrm{D}_{7 \mathrm{~d}}$ ) [45], "Fig. 5". and" Table 1", shows a repetitive sections of bonds. Due to their symmetry ( Table 1: shows comparison of their calculated geometric parameters.

" Table 1": PM3 calculated bond distance and bond angles of (CNT) for (armchair nano cylinder)

\begin{tabular}{||l|l||}
\hline \hline $\begin{array}{l}\text { Bond length }(\AA) \text { and } \\
\text { Bond angles (deg.) }\end{array}$ & nano tube $\mathrm{C}_{140} \mathrm{H}_{28}$ \\
\hline \hline $\mathrm{C}_{1} \mathrm{C}_{8}{ }^{* *}$ & 1.3672 \\
\hline $\mathrm{C}_{1} \mathrm{C}_{22}{ }^{*}$ & 1.4246 \\
\hline $\mathrm{C}_{8} \mathrm{C}_{21}{ }^{*}$ & 1.4245 \\
\hline $\mathrm{C}_{21} \mathrm{C}_{36}{ }^{*}$ & 1.4246 \\
\hline $\mathrm{C}_{1} \mathrm{H}_{141}$ & 1.0996 \\
\hline $\mathrm{C}_{8} \mathrm{H}_{148}$ & 1.0996 \\
\hline $\mathrm{C}_{7} \mathrm{H}_{147}$ & 1.0996 \\
\hline $\mathrm{C}_{14} \mathrm{H}_{156}$ & 1.0996 \\
\hline $\mathrm{C}_{7} \mathrm{C}_{14}{ }^{* *}$ & 1.3672 \\
\hline $\mathrm{C}_{7} \mathrm{C}_{28}{ }^{*}$ & 1.4246 \\
\hline $\mathrm{C}_{21} \mathrm{C}_{28}{ }^{* *}$ & 1.43960 \\
\hline $\mathrm{C}_{21} \mathrm{C}_{36}{ }^{*}$ & 1.40319 \\
\hline
\end{tabular}




\begin{tabular}{||l|l||}
\hline $\mathrm{C}_{28} \mathrm{C}_{35}{ }^{*}$ & 1.40318 \\
\hline$<\mathrm{C}_{8} \mathrm{C}_{1} \mathrm{C}_{22}$ & 120.2804 \\
\hline$<\mathrm{C}_{8} \mathrm{C}_{1} \mathrm{H}_{141}$ & 121.6814 \\
\hline$<\mathrm{C}_{22} \mathrm{C}_{1} \mathrm{H}_{141}$ & 117.8105 \\
\hline$<\mathrm{C}_{14} \mathrm{C}_{7} \mathrm{H}_{147}$ & 121.6904 \\
\hline$<\mathrm{C}_{28} \mathrm{C}_{7} \mathrm{H}_{147}$ & 117.8027 \\
\hline$<\mathrm{C}_{14} \mathrm{C}_{7} \mathrm{C}_{28}$ & 120.2812 \\
\hline$<\mathrm{C}_{1} \mathrm{C}_{8} \mathrm{C}_{21}$ & 120.2816 \\
\hline$<\mathrm{C}_{1} \mathrm{C}_{8} \mathrm{H}_{148}$ & 121.6866 \\
\hline$<\mathrm{C}_{21} \mathrm{C}_{8} \mathrm{H}_{148}$ & 117.8055 \\
\hline$<\mathrm{C}_{8} \mathrm{C}_{21} \mathrm{C}_{28}$ & 121.3644 \\
\hline$<\mathrm{C}_{8} \mathrm{C}_{21} \mathrm{C}_{36}$ & 118.374 \\
\hline$<\mathrm{C}_{28} \mathrm{C}_{21} \mathrm{C}_{36}$ & 118.8102 \\
\hline$<\mathrm{C}_{3} \mathrm{C}_{24} \mathrm{C}_{17}$ & 121.3676 \\
\hline$<\mathrm{C}_{3} \mathrm{C}_{24} \mathrm{C}_{31}$ & 118.3696 \\
\hline$<\mathrm{C}_{17} \mathrm{C}_{24} \mathrm{C}_{31}$ & 118.8098 \\
\hline \hline
\end{tabular}

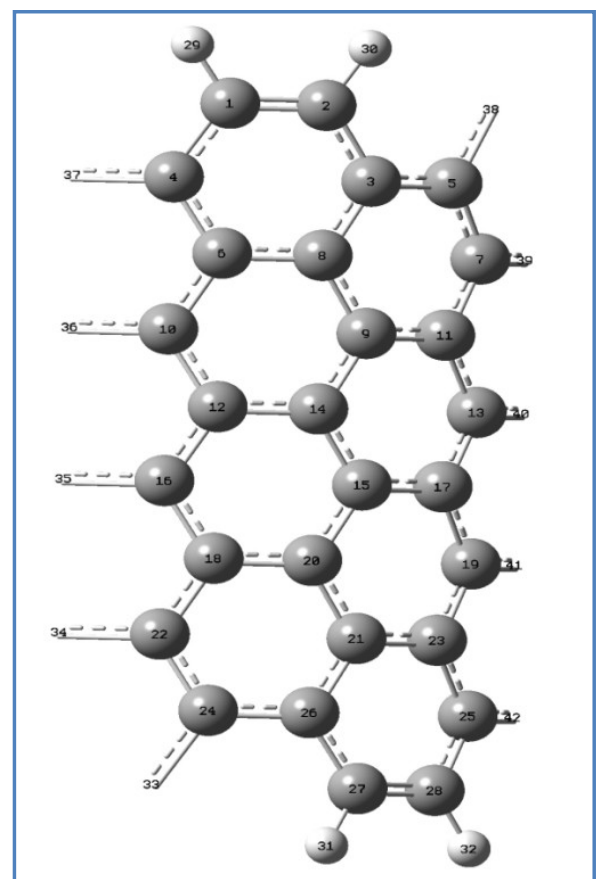

"Fig.5": Repetitive sections of bonds and angles for (CNT) of (armchair nano cylinder) SWCNT at their equilibrium geometries according to point group $\left(\mathrm{D}_{7 \mathrm{~d}}\right)$. SWCNT.

"Table 2": PM3 calculated bond distances of axial bond and circumferential bond for (armchair nano cylinder) SWCNT.

\begin{tabular}{|c|c|c|c|c|c|c|c|c|c|}
\hline \multirow{2}{*}{$\begin{array}{l}\text { Arm } \\
\text { Chair } \\
\text { (SWCNT } \\
\text { ) }\end{array}$} & \multirow[b]{2}{*}{$\begin{array}{c}\text { Diame } \\
\text { ter } \\
(\AA)\end{array}$} & \multirow[b]{2}{*}{$\begin{array}{l}\text { CNT } \\
\text { Length } \\
\text { (§) }\end{array}$} & \multicolumn{7}{|c|}{ Bond length $(\AA)$} \\
\hline & & & $\begin{array}{r}=\mathrm{C} \ldots \\
\mathrm{Ca}\end{array}$ & ${ }_{\mathrm{Ca}}^{-\mathrm{C} . .}$ & $\begin{array}{r}\ldots C . . C \\
a\end{array}$ & $\mathrm{C}=\mathrm{Cc}$ & C...Cc & $\begin{array}{c}\mathrm{C}-\mathrm{C} \\
\mathrm{c}\end{array}$ & $\begin{array}{c}\mathrm{C}- \\
\mathrm{H}\end{array}$ \\
\hline $\begin{array}{l}(7,7) \text { Arm } \\
\text { Chair } \\
\text { SWCNT } \\
\text { D }_{7 \mathrm{~d}} \\
\end{array}$ & 10.041 & 12.901 & 1.4246 & ---- & $\begin{array}{l}1.4031 \\
1.4346 \\
1.4301 \\
1.4044 \\
\end{array}$ & $\begin{array}{c}1.367 \\
0\end{array}$ & \begin{tabular}{|l|}
1.4276 \\
1.4292 \\
1.3974 \\
1.4395 \\
\end{tabular} & - & $\begin{array}{c}1.099 \\
6\end{array}$ \\
\hline
\end{tabular}

\section{C-Ca: axial bond. $\quad$ C-Cc: circumferential bond}

Noting that the C-Ca bonds in the angular SWCNTs are conjugated double bonds for all of different rings layer, but it may be connect to ( $\mathrm{CC}$ double or single or conjugated double bond). The $\mathrm{C}-\mathrm{Cc}$ bonds are 
double or conjugated double bond of carbon (armchair nano cylinder) SWCNT, and double or conjugated double bond or single bond of carbon nanotube. SWCNT.

The $\mathrm{C}=\mathrm{Cc}$ bond decrease with increasing of rings layer. For $(\mathrm{C}-\mathrm{H})$ and $(\mathrm{C}-\mathrm{Cc})$ bonds are longer in

Also note that (...C...Ca), increase in length from outer to centre in CNT, and decrease in length from outer to centre in CNT. "Fig. 5", "Table 1".

"Table 3": shows some physical properties of calculated for (nano cylinder) armchair SWCNT at the equilibrium geometry.

"Table 3": Some physical properties of the calculated for (armchair nano cylinder) SWCNT at the equilibrium geometry by using Mopac2000 program.

$\Delta \mathrm{H}_{\mathrm{f}}=$ heat of formation, $\mathrm{HOMO}=$ Highest Occupied molecular orbital, $\mathrm{LUMO}=$ Lowest $\quad$ Unoccupied molecular orbital, $\Delta \mathrm{E}=$ The difference in energy levles.

$\Delta \mathrm{H}_{\mathrm{f}}$ increase with increasing the length of CNT, $\Delta \mathrm{E}$ (LUMO-HOMO) decrease with increasing the length of CNT that prove their electrical conductivity increased with increasing number of rings layer. Dipole moment $\mu$ is zero for all, because the CNT has center of inversion symmetry element. same relation noticed for vibrations modes (IR active).

\begin{tabular}{|c|c|c|c|c|c|c|}
\hline $\begin{array}{l}\text { Arm Chair } \\
\text { (SWCNT) }\end{array}$ & $\begin{array}{l}\text { M. Wt. } \\
\text { g/ mol }\end{array}$ & $\Delta \mathbf{H}_{\mathrm{f}} \mathrm{kcal} / \mathrm{mol},(\mathrm{kJ})$ & $\boldsymbol{\mu}$ (debye) & $\begin{array}{c}\text { HOMO } \\
(\mathrm{eV})\end{array}$ & $\begin{array}{l}\text { LUMO } \\
(\mathrm{eV})\end{array}$ & $\begin{array}{r}\Delta \mathbf{E}(\mathrm{eV}) \\
\text { LUмо-номо }\end{array}$ \\
\hline $\begin{array}{l}\text { Nano cylinder } \\
\mathrm{C}_{140} \mathrm{H}_{28}\end{array}$ & 1709.761 & $\begin{array}{c}721.486 \\
3018.699\end{array}$ & 0.000 & -7.403 & -2.437 & 4.066 \\
\hline
\end{tabular}

\subsection{Vibration frequencies assignment of armchair nano cylinder $\left(\mathrm{C}_{140} \mathrm{H}_{28}\right)$ SWCNT.}

The armchair CNT posses 498 fundamental vibrations (3N-6). Inspection of its irreducible representation, as defined by the symmetry character table, results in the following modes of vibration;

Tvibration $=\Gamma_{\text {total }}-($ rotation $+\Gamma$ translation $)=3 \mathrm{~N}-6=498$

Tvibration $=36 \mathrm{E}_{3} \mathrm{u}+36 \mathrm{E}_{3} \mathrm{~g}+36 \mathrm{E}_{2} \mathrm{~g}+36 \mathrm{E}_{2} \mathrm{u}+35 \mathrm{E}_{1} \mathrm{u}+35 \mathrm{E}_{1} \mathrm{~g}+18 \mathrm{~A}_{1} \mathrm{u}+17 \mathrm{~A}_{2} \mathrm{~g}+18 \mathrm{~A}_{1} \mathrm{~g}+17 \mathrm{~A}_{2} \mathrm{u}=498$

These are $87 \mathrm{IR}$ active $\left(35 \mathrm{E}_{1} \mathrm{u}\right.$, and $\left.17 \mathrm{~A}_{2} \mathrm{u}\right)$. Their assignments are as follow:

Relative to the $\sigma_{\mathrm{h}}$ reflection the vibration modes are classified as symmetric and antisymmetric modes.

\subsubsection{CH stretching vibration}

These are 28 in number, the displacement vectors of which are located at the $\mathrm{H}$ atoms. Their calculated vibration frequencies (IR active) as modes range from (3004.3- 3029.0 $\mathrm{cm}^{-1}$ ), Inspecting the values in "Table 4".

\subsubsection{Ring (CCC) stretching vibration}

Their displacement vectors are not located at definite $\mathrm{C}$ atoms as could be seen from the atomic displacement vectors. Their calculated vibration frequencies (IR active) as modes range from (1409.13- 1796.6 $\mathrm{cm}^{-1}$ ), Inspecting the values in "Table 4".

\subsubsection{In-plane $\mathrm{CH}$ bending vibration $(\delta \mathrm{CH})$}

There are as few as the $\mathrm{C}-\mathrm{H}$ bonds. Their displacement vectors are mainly located at the corresponding $\mathrm{H}$ atoms. Their calculated vibration frequencies (IR active) as modes range from $\left(149.7-1067.7 \mathrm{~cm}^{-1}\right.$ ), Inspecting the values in "Table 4".

\subsubsection{In-plane $(\mathrm{CCC})$ bending vibration $(\delta \mathrm{CCC})$}

Their calculated vibration frequencies (IR active) as modes range from $\left(149.7-1343.7 \mathrm{~cm}^{-1}\right.$ ), Inspecting the values in "Table 4".

\subsubsection{Out of plane $\mathrm{CH}$ bending vibration $(\gamma \mathrm{CH})$}

Their calculated vibration frequencies (IR active) as modes range from $\left(270.1-1288.6 \mathrm{~cm}^{-1}\right)$, Inspecting the values in "Table 4".

\subsubsection{Out of plane ring bending vibration $(\gamma \mathrm{CCC})$}

The modes include puckering deformations, as well as breathing vibrations of the whole ring. Their calculated vibration frequencies (IR active) as modes range from $\left(256.3-1363.9 \mathrm{~cm}^{-1}\right)$, Inspecting the values in "Table 4". includes the calculated frequencies as calculated applying semi-empirical methods (PM3) by Gaussian03 program and IR absorption intensities of the vibration modes. Commonly known, the vibrations 
Theoretical Study for Electronic and Vibrational properties of nano cylinder $\left(C_{140} H_{28}\right)$.

with (intensity $=0.0$ ) are forbidden (IR inactive, Ramman active), those with (intensity $\neq 0.0$ ) are allowed (IR active, Ramman inactive).

"Table 4".Vibration frequencies and IR absorption intensities for CNT $\left(\mathrm{C}_{140} \mathrm{H}_{28}\right)$ molecule as calculated applying G03 program.

\begin{tabular}{|c|c|c|c|}
\hline $\mathbf{E}_{1 \mathrm{u}}$ (in) & Symmetry \& description & PM3 Freq. cm $^{-1}$ & Intensity $\mathrm{km} / \mathrm{mol}$ \\
\hline$v_{489}$ & CH str. & 3029.03 & 9.0755 \\
\hline$v_{481}$ & CH str. & 3004.26 & 117.43 \\
\hline$v_{461}$ & C-C str & 1796.56 & 4.349 \\
\hline$v_{457}$ & $\mathrm{C}=\mathrm{C}$ str & 1793.22 & 14.884 \\
\hline$v_{435}$ & $\mathrm{C}=\mathrm{C}$ str & 1722.35 & 2.539 \\
\hline$v_{414}$ & $\mathrm{C}=\mathrm{C}$ str & 1675.17 & 0.278 \\
\hline$v_{403}$ & C-C str & 1643.15 & 1.444 \\
\hline$v_{399}$ & $\operatorname{ring}\left(\mathrm{CCC}_{\text {str. }}\right)$ & 1602.76 & 0.0197 \\
\hline$v_{369}$ & $\operatorname{ring}\left(\mathrm{CCC}_{\text {str. }}\right)$ & 1556.18 & 0.4601 \\
\hline$v_{363}$ & C- C str & 1536.56 & 8.336 \\
\hline$v_{352}$ & $\operatorname{ring}\left(\mathrm{CCC}_{\text {str. }}\right)$ & 1498.85 & 17.8001 \\
\hline$v_{334}$ & $\operatorname{ring}\left(\mathrm{CCC}_{\text {str. }}\right)$ & 1409.13 & 30.762 \\
\hline$v_{321}$ & Sring $(\delta \mathrm{CCC})$ & 1343.71 & 0.2808 \\
\hline$v_{313}$ & $\gamma \mathrm{CH}($ wagg. $)+\gamma$ ring $(\gamma \mathrm{CCC})$ & 1288.64 & 6.322 \\
\hline$v_{295}$ & $\gamma \mathrm{CH}$ (wagg.) & 1152.63 & 5.5834 \\
\hline$v_{274}$ & 8CH(siccer.) & 1067.71 & 1.0663 \\
\hline$v_{260}$ & $\delta \mathrm{CH}$ (siccer.) & 1004.26 & 0.076 \\
\hline$V_{247}$ & $\gamma$ ring $(\gamma \mathrm{CCC})+\gamma \mathrm{CH}$ & 964.564 & 1.2371 \\
\hline$v_{241}$ & $\gamma \mathrm{CH}($ twiss. $)+\gamma$ ring $(\gamma \mathrm{CCC})$ & 945.735 & 0.0122 \\
\hline$v_{227}$ & $\gamma \mathrm{CH}($ twiss. $)+\gamma$ ring $(\gamma \mathrm{CCC})$ & 896.6 & 5.1302 \\
\hline$v_{216}$ & $\delta \mathrm{CH}+\delta$ ring $(\delta \mathrm{CCC})$ & 858.66 & 22.623 \\
\hline$V_{204}$ & $\gamma \mathrm{CH}($ wagg. $)+\gamma$ ring $(\gamma \mathrm{CCC})$ & 830.641 & 46.341 \\
\hline$v_{194}$ & $\delta \mathrm{CH}($ rock) & 812.82 & 125.337 \\
\hline$v_{153}$ & $\gamma \mathrm{CH}($ twiss. $)+\gamma$ ring $(\gamma \mathrm{CCC})$ & 674.771 & 1.1662 \\
\hline$v_{150}$ & $\delta \mathrm{CH}+\delta$ ring $(\delta \mathrm{CCC})$ & 664.392 & 11.594 \\
\hline$v_{143}$ & $\delta \mathrm{CH}($ rock. $)++\delta$ ring $(\delta \mathrm{CCC})$ & 653.804 & 7.2941 \\
\hline$v_{124}$ & $\gamma \mathrm{CH}($ wagg. $)+\gamma$ ring $(\gamma \mathrm{CCC})$ & 602.856 & 3.0915 \\
\hline$V_{99}$ & $\gamma \mathrm{CH}$ (twiss. $)+\gamma$ ring $(\gamma \mathrm{CCC})$ & 492.552 & 22.087 \\
\hline$v_{95}$ & $\gamma \mathrm{CH}($ twiss. $)+\gamma$ ring $(\gamma \mathrm{CCC})$ & 481.314 & 1.5762 \\
\hline$v_{82}$ & $\gamma \mathrm{CH}($ twiss. $)+\gamma$ ring $(\gamma \mathrm{CCC})$ & 436.045 & 4.3508 \\
\hline$v_{61}$ & $\gamma \mathrm{CH}($ twiss. $)+\gamma$ ring $(\gamma \mathrm{CCC})$ & 357.166 & 2.9102 \\
\hline$v_{59}$ & $\gamma \mathrm{CH}($ twiss. $)+\gamma$ ring $(\gamma \mathrm{CCC})$ & 346.147 & 1.0289 \\
\hline$v_{44}$ & $\gamma$ ring $(\gamma \mathrm{CCC})+\gamma \mathrm{CH}$ (wagg.) & 284.641 & 0.935 \\
\hline$v_{38}$ & $\gamma \mathrm{CH}($ wagg. $)+\gamma$ ring $(\gamma \mathrm{CCC})$ & 270.122 & 5.758 \\
\hline$v_{13}$ & $\delta \mathrm{CH}($ rock.) $+\delta$ ring $(\delta \mathrm{CCC})$ & 149.751 & 6.048 \\
\hline $\mathrm{A}_{2} \mathrm{u}$ & Out plan & & \\
\hline$v_{483}$ & CH str. & 3008.892 & 616.385 \\
\hline$v_{442}$ & $\mathrm{C}=\mathrm{C}$ str & 1765.63 & 14.298 \\
\hline$v_{409}$ & $\mathrm{C}=\mathrm{C}$ str & 1654.39 & 3.1335 \\
\hline$v_{387}$ & ring $\left(\mathrm{CCC}_{\text {str. }}\right)$ elonga. & 1600.18 & 4.349 \\
\hline$v_{367}$ & ring $\left(\mathrm{CCC}_{\text {str. }}\right)$ elonga. & 1542.98 & 2.304 \\
\hline$v_{348}$ & ring $\left(\mathrm{CCC}_{\text {str. }}\right)$ elonga. & 1480.57 & 0.2087 \\
\hline$v_{329}$ & $\gamma$ ring $(\gamma \mathrm{CCC})$ & 1363.96 & 100.904 \\
\hline$v_{303}$ & $\operatorname{ring}\left(\mathrm{CCC}_{\text {str. }}\right)$ & 1193.15 & 5.645 \\
\hline$v_{284}$ & $\gamma \mathrm{CH}$ (twist.) & 1114.75 & 20.534 \\
\hline$v_{260}$ & $\gamma \mathrm{CH}$ (twist.) & 1028.51 & 1.906 \\
\hline$v_{188}$ & $\delta \mathrm{CH}($ rock) & 801.216 & 4.297 \\
\hline$v_{147}$ & $\gamma$ ring $(\gamma \mathrm{CCC})+\gamma \mathrm{CH}($ breath. $)$ & 660.794 & 0.366 \\
\hline$v_{138}$ & $\gamma$ ring $(\gamma \mathrm{CCC})+\gamma \mathrm{CH}$ (breath.) & 642.957 & 2.8819 \\
\hline$v_{109}$ & $\delta \mathrm{CH}($ rock $)+\delta$ ring $(\delta \mathrm{CCC})$ & 518.928 & 10.4807 \\
\hline$v_{67}$ & $\delta \mathrm{CH}($ rock.) $)+\delta$ ring $(\delta \mathrm{CCC})$ & 376.334 & 1.735 \\
\hline$v_{35}$ & $\gamma$ ring $(\gamma \mathrm{CCC})($ breath. $)$ & 256.287 & 0.4318 \\
\hline$v_{15}$ & $\delta \mathrm{CH}($ rock.) $)+\delta$ ring $(\delta \mathrm{CCC})$ & 152.02 & 0.7306 \\
\hline
\end{tabular}

"Fig. 6":Shows the vibration pictures for some modes of the (nano cylinder) CNT (Armchair), as calculated applying semi-empirical methods (PM3) by Gaussian 03 program. 


\subsection{The whole relations of (armchair nano cylinder) CNT.}

The C-C frequencies different values are calculated for the different bonds of CNT. As expected the differences in the vibration frequencies are due to the different $\mathrm{C}-\mathrm{C}$ force constants, The frequencies of the vibration modes in "Table 4", point to systematic correlations between the frequencies of different species. This is mostly obvious in the case of the $\mathrm{C}-\mathrm{H}$ stretching vibrations, for which the following general relation holds:

vsymCHstr. $\left(3029.03 \mathrm{~cm}^{-1}\right)>v_{\text {asym. }}$ CHstr. $\left(3008.892 \mathrm{~cm}^{-1}\right)$

$v$ sym $\mathrm{CC}_{\text {str. }} \cdot\left(1796.56 \mathrm{~cm}^{-1}\right)>v_{\text {asym }} \mathrm{CC}_{\text {str }} \cdot\left(1765.6 \mathrm{~cm}^{-1}\right)$

$v$ sym $\delta$ ring $\left(664.39 \mathrm{~cm}^{-1}\right)>v_{\text {asym. }}$. ring. $\left(518.928 \mathrm{~cm}^{-1}\right)$

$v \operatorname{sym} \gamma \operatorname{ring}\left(1288.64 \mathrm{~cm}^{-1}\right)<v_{\text {asym }} \gamma \operatorname{ring}\left(1363.96 \mathrm{~cm}^{-1}\right)$

$v \operatorname{sym} \delta \mathrm{CH}\left(1067.71 \mathrm{~cm}^{-1}\right)>v_{\text {asym }} \delta \mathrm{CH}\left(801.216 \mathrm{~cm}^{-1}\right)$

$v \operatorname{sym} \gamma \mathrm{CH}\left(1288.64 \mathrm{~cm}^{-1}\right)>v_{\text {asym }} \gamma \mathrm{CH}\left(1114.75 \mathrm{~cm}^{-1}\right)$

This interesting result shows that in general the $\mathrm{C}-\mathrm{H}$ and $\mathrm{C}-\mathrm{C}$ stretching frequencies of the $\mathrm{CNT}$ for symmetric modes are higher than those of the asymmetric modes of CNT. molecule.

\subsection{The results include the relation for IR absorption intensities.}

The calculated IR absorption intensities values range from (125.337_0.0122 km/mol ) for symmetric mods $\left(E_{1} \mathrm{u}\right.$, and the calculated IR absorption intensities values range from $(1 \overline{00} .94-0.298 \mathrm{~km} / \mathrm{mol})$ for asymmetric mods $\left(\mathrm{A}_{2} \mathrm{u}\right)$.

Finally, the calculated vibration frequencies (IR-active) show that vibration frequency values of ( C-C

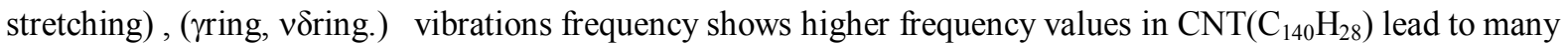
more electronic and mechanical applications.

"Table 5": Calculated Vibration frequencies of (nano cylinder) armchair SWCNT applying G03 program by PM3 method.

\begin{tabular}{|l||c|c|c|c|}
\hline \hline Arm Chair (SWCNT) & $\mathbf{C}-\mathbf{H}_{\text {str. }}$ & $\mathbf{C}-\mathbf{C a}_{\text {str }}$ & $\mathbf{C}=\mathbf{C c}_{\text {str. }}$ & $\mathbf{C}_{--C \mathbf{c}_{\text {str }}}$ \\
\hline \hline (nano cylinder) armchair SWCNT & $\mathbf{3 0 2 9 . 1 1}$ & $\mathbf{1 6 0 2 . 7 0}$ & $\mathbf{1 7 9 3 . 2 2}$ & $\mathbf{1 7 9 6 . 5 0}$ \\
$\mathrm{C}_{140} \mathrm{H}_{28}$ & $\mathbf{E}_{\mathbf{1}} \mathbf{u}$ & $\mathbf{E}_{\mathbf{1}} \mathbf{u}$ & $\mathbf{E}_{\mathbf{1}} \mathbf{u}$ & $\mathbf{E}_{\mathbf{1}} \mathbf{u}$ \\
\hline
\end{tabular}

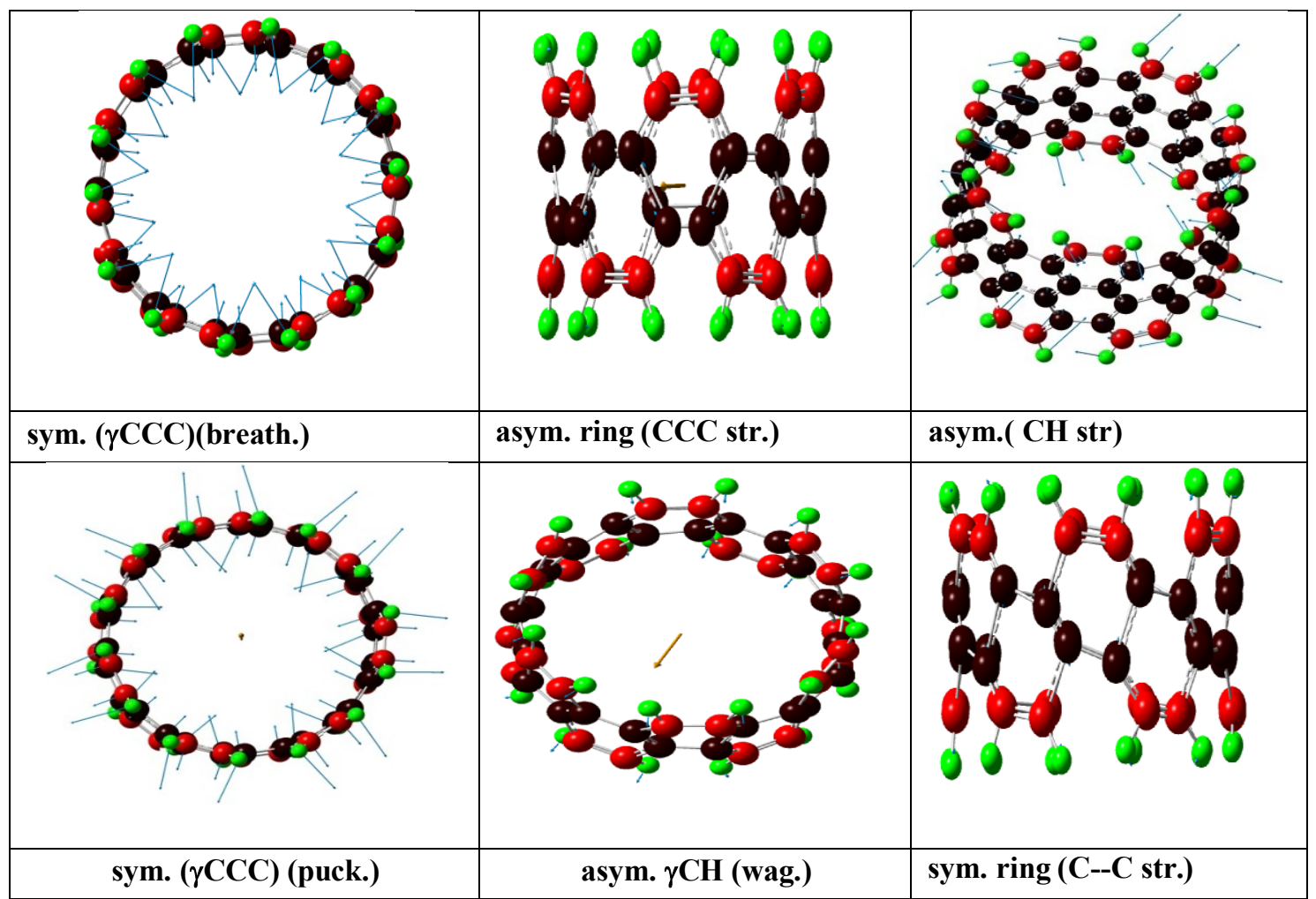

"Fig. 6". The graphical pictures of some vibration modes for CNT (armchair) as calculated applying G03 program. 
Finally, the calculations show that, similar to the carbon nanotubes [46-47], the charge densities are mainly concentrated at the circumferential carbon and hydrogen atoms of SWCNT, parallel with their physical properties for electrical conductivity. The axial carbon atoms have diminishing charges from outer to centre. The $\mathrm{H}$ atoms are positively charged, the $\mathrm{C}$ atoms are of the negative charge, "Fig. 7".

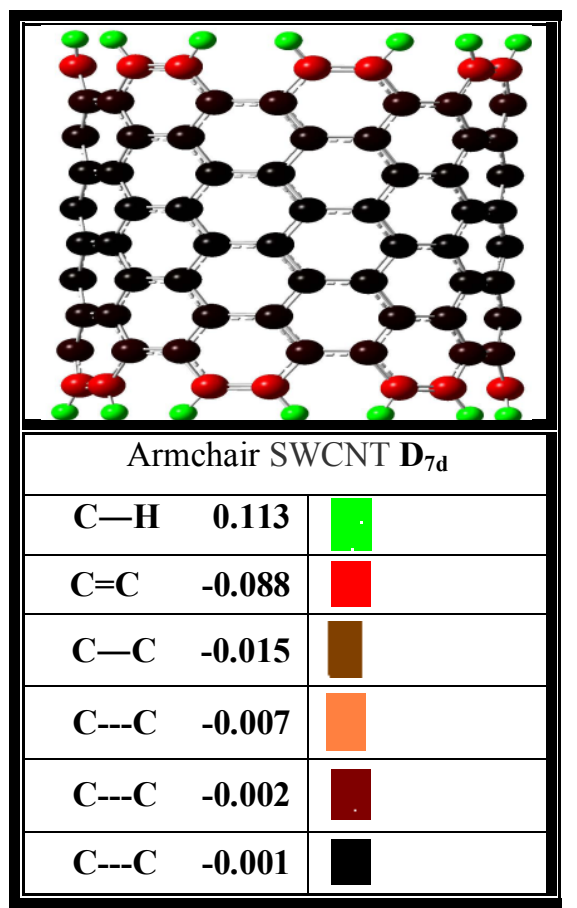

"Fig. 7". Distribution of charge density at the atoms of (nano cylinder) armchair SWCNT as calculated applying G03 program.

Note. All calculations were done applying the G03 program of Pople et al . [30].

\section{Conclusion}

Quantum mechanics semi-empirical (PM3) calculations were carried out with Gaussian 03 program, for investigated the result In order to calculate the vibration frequencies modes that active in infrared. Comparison of the Vibration modes which were active in IR for the (nano cylinder) armchair nanotube $\left(\mathrm{C}_{140} \mathrm{H}_{28}\right)$. Vibrational motion of atoms decreases the electrical conductivity of nanotube and limits the performance of nanotransistors and other electronic devices based on them. Similarly, the stiffness of a nanotube and its capability for transporting heat is reduced with increasing defect density[48,49] They allow a comparative view of the charge density at the carbon atom too. The calculations show that, the charge densities are mainly concentrated at the hydrogen atoms (positively charged) and at the outer circumferential carbon atoms (negatively charge). The axial carbon atoms and the circumferential carbon atoms have diminishing charges from outer to the centre of the CNTs. They can have metallic properties (armchair, some zigzag) depending on their structure. CNTs are much better conductors of electricity than copper nanowires because there is less scatter of electrons. Nanotubes are exceptional ballistic conductors, which can be used in a variety of nanodevices that can operateat room temperature. Nanotubes possess extraordinary mechanical properties and are among the strongest materials known.

\section{Acknowledgements}

The calculated vibration frequencies (IR-active) show that vibration frequency values of ( C-C stretching), ( $\gamma$ ring, voring.) vibrations frequency shows higher frequency values in $\mathrm{CNT}\left(\mathrm{C}_{140} \mathrm{H}_{28}\right)$ lead to many more electronic and mechanical applications. Vibrational motion of atoms decreases the electrical conductivity of nanotube.

\section{References}

[1] S. Iijima ,Nature.Helical microtubules of graphitic carbon . 1991, 354, 56-58.

[2] S. Iijima and T. Ichlhashi, Nature Article, Single-shell carbon nanotubes of $1 \mathrm{~nm}$ diameter . 1993, 361, 333-334.

[3] D. S. Bethune, C. H. Kiang, M. S. Devries, G. Gorman, R. Savoy, J. Vazquez and R. Beyers ,Nature, Cobalt-catalyzed growth of carbon nanotubes with single-atomic-layer walls. 1993, 363, 605-607.

[4] Thess A. et al. Science, Crystalline ropes of metallic carbon nanotubes. 1996, 273 (5274):, 483-487. 
[5] R. Saito, G. Dresselhaus, and M. S. Dresselhaus, in Physical Properties of Carbon Nanotubes (Imperial College Press, London), 1998, ISBN: 1-86094-093-5.

[6] A. G. Rinzler et al., Science, Unraveling Nanotubes: Field Emission from an Atomic Wire. 1995 ,269 (5230): $1550-1553$.

[7] S. J. Tans et al., Nature, Quantum Enginering : Collections : Supplements. 1997, 386, 474-477.

[8] M. Kociak et al., Phys. Rev. Lett. Department of Physics | Temple University. 2001, 86, 967.

[9] P. Kim, L. Shi, A. Majumdar and P. L. McEuen , Phys. Rev. Lett. Thermal transport measurements of individual multiwalled nanotubes. 2001,87(21), 215502 .

[10] P. M. Ajayan, O. Stephan, C. Colliex and D.Trauth. Science, 1994, 265, 1212- 2114.

[11] S. Iijima, C. Brabec, A. Maiti and J. Bernholc, J. Chem. Phys. 1996, 1042089.

[12] Chopra N. G., Benedict L. X., Crespi V. H., Cohen M. L., Louie S. G. and Zettl A. Nature 1995, "Fully Collapsed Carbon Nanotubes",377, 135.

[13] R. S. Ruoff and D. C. Lorents 1995 Carbon 33925

[14] H. W. Kroto, J. R.Heath, S. C. O. Brien, R. F. Curl and R. E. Smalley, Nature ,1985, 318, 162-163. London.

[15] C. Trallero-Giner, F. Garci'a-Moliner, V. Velasco, and M.Cardona, Phys. Rev. 1992, B 45, 11944.

[16] T. D. Krauss and F. W. Wise, Phys. Rev. Lett., Coherent Acoustic Phonons in a Semiconductor Quantum . $1997,79,5102$.

[17] J. H. Hodak, A. Henglien, and G. V. Hartland, J. Chem. Phys., Applied Physics of Carbon Nanotubes. 1999,111, 8613.

[18] M. A. Stroscio and M. Dutta, Phys. Rev., 1999, B 60, 7722 .

[19] L. T. Chadderton, J. Phys. Chem.. Applied Physics of Carbon Nanotubes. Solids ,1993,54, 1027.

[20] X. Xiaoyu, L. Ji-Xing, and O. Y. Zhong-Can, Mod. Phys. Lett., Applied Physics of Carbon Nanotubes. $1995,9,1649$.

[21] V.Mitin, V.Kochelap, and M. A.Stroscio, Quantum Heterostructures:Microelectronics and Optoelectronics -Cambridge University Press, NewYork, 1999.

[22] MMJ. Treacy, TW. Ebbesen, TM. Gibson ,Nature, Exceptionally High young's modulus observed for individual carbon nanotubes. 1996, 381:680-687.

[23] EW. Wong, PE. Sheehan and CM. Lieber, Nanobeam mechanics: elasticity, strength, and toughness of nanorods and nanotubes. Science 1997; 277:1971-1975.

[24] MR. Falvo, GJ .Clary, RM .Taylor, V .Chi, Brooks FP, S .Washburn et al. Nature, Bending and buckling of carbon nanotubes under large strain. 1997; 389:582-4.

[25] C. Bower, R. Rosen, L. Jin, J. Han, O. Zhou. Applied Physics Letters, Deformation of carbon nanotubes in nanotube-polymer composites. $1999 ; 74(22): 3317-9$.

[26] G. Overney, W. Zhong, D. Tomanek, Structural rigidity and low frequency vibrational modes of long carbon tubules. Zeitschrift Fur Physik D-Atoms Molecules and Clusters. 1993, 27(1):93-96.

[27] JP. Lu Journal of the Physics and Chemistry of Solids. 1997;58(11):1649-52. Elastic properties of single and multilayered nanotubes.

[28] BI. Yakobson, MP. Campbell, CJ. Brabec, Bernholc J. Computational Materials Science, High strain rate fracture and C-chain unraveling in carbon nanotubes. 1997, 8(4):341-8.

[29] J. Bernholc, CJ. Brabec, M. Nardelli, A. Maiti, C. Roland, BI.Yakobson, Theory of growth and mechanical properties of nanotubes. Applied Physics A-Materials Science and Processing. ,1998, 67(1):39-46.

[30] M. J. Frisch, G. W. Trucks, H. B. Schlegel, G. E. Scuseria, M. A. Robb, Gaussian, Inc. Pittsburgh, PA, (2003).

[31] P. Bischoff, MOLEK 9000 Program, OCI, Uni. Heidelerg, Private Communicatio Pople, J. A.; Gaussian, Inc. Pittsburgh, PA, (2003).

[32] A. Jorio, R. Saito, J.H. Hafner, C.M. Liebre, M. Hunter, T. Mcclur and G. Dresselhaus, phys. Rev. Lett. $2001,86,1118$.

[33] N. Hamada, S. Sawada and A. Oshiyama, Phys. Rev. Let., The American Physical Society in the figure, which are useful to distinguish the crystal structures of tubules. 1992, 68, 1579.

[34] Y. Wang and X. Jing, Polym. Adv. Technol., "Intrinsically conducting polymers for electromagnetic interference shielding," Polymers for Advanced Technologies. 2005, 16, 344-351.

[35] T. Durkop, S.A. Getty, E. Cobas and M.S. Fuhrer, Nano Lett. 2004, 4, 35-39.

[36] B.I. Yacobson and R.E. Smalley, "Fullerene Nanotubes; C1000, 000 and Beyond," American Scientist,. 1997, vol. 85, pp. $324-337$.

[37] A.B. Dalton, J.N.Coleman, B. McCarthy, P.M. Ajayan, S. Lefrant, P. Bernier, W. Blau and H.J. Byme, J. Phys. Chem. 2000, B. 104,1012 .

[38] S. Reich, C. Thomsen, J. -VCH. Maultzsch Wiley, Weinheim, Carbon Nanotubes: Basic Concepts and Physical Properties. (2004), ix +214 pp. [ISBN 3-527-40386-8].

[39] L. Vitali, Bughard M., Schneider M.A., LeiLiu Y.Wu., Jayanthi C. and Kem K., Max planck institute for Solid State Research, 2004, Lett. 93, 136, 103 .

[40] U. Kuhlman, H. Jantoljak, N. Pfander, P. Bernier, C. Journet and C. Thomsen, Chem. Phys. Lett. 1998, 294, $234-237$.

[41] Science direct-surface science Reports; Electronic and Vibrational properties of chemically modified (SWCNTs), Article Tool book, Max-plank-Institutfuer, Germany. 2005, vol. 58, Issues 4, August, p. 1-5.

[42] O.E. Alon, Physical Review, Number of raman- and infrared-active vibrations in single-walled carbon nanotubes, 2001, Vol.63, pp. 201403-201406.

[43] Li CY. and TW. Chou, Appl. Phys. ,"nanotube-based nanomechancial resonators". 2003, Lett. 84, 121-123

[44] CY.Wang, CQ. Ru, A. Mioduchowski ,J. Appl. Phys., 'Free vibration of multiwall ... nanotubes”, 2005, vol.97, no. 11, paper 114323.

[45] H. N. Al-Ani, "Theoretical Study of Vibration Modes for Cyclacene and Collarene Molecules (Construction Units of Carbon Canotubes)", M.Sc. Thesis, College of Science, University of Baghdad, (2009).

[46] M. Krcmar, W.M. Saslow and A. Zangwill, J. Appl. phys., , "Electrostatic of Conducting Nanocylinder" (2003), 93 , pp. 34953500 .

[47] T. W. Odom, J. Huang, P.Kim and C. M. Lieber, J. Phy. Chem., "Structure and Electronic Properties of CNT.” (2000), 104, ,27942809 .

[48] L. Vitali, M.Bughard, M.A.Schneider, Lei Liu, S.Y.Wu, C.S. Jayanthi, and K. Kern Science 275, Phonon Spectromicroscopy of Carbon Nanostructures with Atomic ResolutionPhys. Rev. Lett. 93, 136103, (2004), pages 187-191.

[49] MAX PLANCK SOCIETY Press Release Max Planck Society for the Advancement of Science(2004) C / 3002 (31) September 27 th. 